\title{
Cost-efficiency of Clinical Pharmacy Services at Ministry of Health Hospital, Riyadh City, Saudi Arabia
}

\author{
Yousef Ahmed Alomi* iD, The \\ Former General Manager of General \\ Administration of Pharmaceutical Care, \\ Former Head, National Clinical Pharmacy \\ and Pharmacy Practice. Former Head, \\ Pharmacy R\&D Administration, Ministry of \\ Health, Riyadh, SAUDI ARABIA.
}

Sultan Mohammed Al-Jarallah, Head, Ambulatory Care Pharmacy, Oncology and Hematology Clinical Pharmacist, Pharmaceutical Care Department, Security Forces Hospital, Riyadh, SAUDI ARABIA.

Faiz A. Bahadig, Informatics Pharmacist, Pharmaceutical Care Department, King Abdul-Aziz Medical, City-WR-Jeddah, Ministry of National Guard, SAUDI ARABIA.

\section{Correspondence:}

Dr. Yousef Ahmed Alomi, The Past General Manager of General Administration of Pharmaceutical Care, Head, National Clinical Pharmacy and Pharmacy Practice, Head, Pharmacy R\&D Administration, Ministry of Health, Riyadh-11392, SAUDI ARABIA.

Phone no: +966504417712

E-mail:yalomi@gmail.com
Received: 18-12-2019

Approved: 26-3-2019

Copyright: (c) the author(s),publisher and licensee Pharmacology, Toxicology and Biomedical Reports. This is an open-access article distributed under the terms of the Creative Commons Attribution NonCommercial License, which permits unrestricted non-commercial use, distribution, and reproduction in any medium, provided the original work is properly cited.

This is an open access article distributed under the terms of the Creative Commons Attribution-NonCommercial-ShareAlike 4.0 License

Access this article online

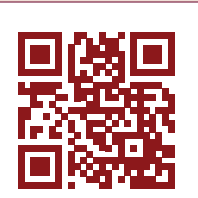

www.ptbreports.org

DOI:

10.5530/PTB.2019.5.33

\begin{abstract}
Objectives: The primary aim of this study was to estimate cost-efficiency of clinical pharmacy services in Saudi Arabia by using American model. Methods: This is a simulation study which includes data of all 5 months of providing clinical pharmacy services for adults organized by local drug information center at biggest public hospital in Riyadh city. Ten clinical pharmacists and expert trained pharmacists provided clinical pharmacy services at the hospital including drug information services, poisoning control services, therapeutic drug monitoring services, orthopedic services, oncology services, Pharmacoeconomical services and pain management services. All pharmacists should document the clinical pharmacy activities on a monthly basis. The estimated cost avoidance was calculated by using two International Studies Models, expressed in US dollars (USDs). The cost considered were the expected results of drug-related inquiries, poisoning information calls if not resolved and pharmacist intervention for all other clinical pharmacy services. Results: The total average estimated monthly cost avoidance from all clinical services $(17,554,931.46$ USD) with cumulative cost avoidance was $65,830,992.97$ USD during the study period. The estimated total cost avoidance annually was $210,659,177.52$ USD. The highest cost avoidance came from poisoning services, whose estimated cost avoidance was $61.8 \%$ $(9,110,026.40$ USD) followed by drug information services, whose estimated cost avoidance was $26.8 \%(4,711,273.50$ USD) and other clinical pharmacy services, whose estimated cost avoidance was $11.4 \%(2,006,444.63$ USD). Each USD invested in the clinical pharmacist estimated cost avoidance was an average of 28.76 USD. Each USD invested in the clinical pharmacist provides poisoning control services estimated cost avoidance was an average of 17.77 USD and each USD invested in the clinical pharmacist provide drug information services estimated cost avoidance was an average of 7.7 USD. Conclusion: The clinical pharmacy services had a very high economic impact on the healthcare system in the local public hospital. In the future, we are targeting to expand the clinical pharmacy services to prevent drug-related cost in the Kingdom of Saudi Arabia.

Key words: Cost-efficiency, Clinical pharmacy, Ministry of Health, Riyadh, Saudi Arabia.
\end{abstract}

\section{INTRODUCTION}

The clinical pharmacy services was started in the Kingdom of Saudi Arabia in the late-1970s, ${ }^{1,2}$ whereas it was started at the Ministry of Health hospitals in the mid-1980s. ${ }^{1,2}$ Several clinical pharmacy services founded at that time included but not limited to the drug information services, therapeutic drug monitoring services, rounds with clinical teams and total parental nutrition. ${ }^{1,2}$ The clinical pharmacy services focused on drug information, formulary management system, antibiotics monitoring and rounds with medical and surgical teams. After several years of starting clinical pharmacy services, the measurement of impact of the services on patient care and on the healthcare system was investigated in Saudi Arabia. Previously, several studies have illustrated the clinical outcome and economic impact of critical pharmacy services. ${ }^{3}$ Some investigations focused on, for instance, drug information services, therapeutic drug monitoring services and on total parenteral nutrition. ${ }^{4-8}$ Other studies have focused on the general clinical activities, for instance, pharmacists interventions and prevention of medications errors. ${ }^{9-13}$ The studies on the general clinical pharmacy services on the measurement of economic impact investigated overseas countries; however, to the best of our knowledge, there are no similar studies conducted in the Saudi Arabia, Gulf and Middle Eastern countries. ${ }^{14-17}$ Therefore, in this study, we aimed to explore the cost-efficiency of clinical pharmacy services in Riyadh city, Saudi Arabia.

\section{METHODS}

This is a simulation study which included data of all 5 months of providing clinical pharmacy services to adults organized by local drug information center at public hospital, in Riyadh city, Kingdom of Saudi Arabia. In this study, 10 clinical pharmacists and expert trained pharmacists provided clinical pharmacy services which included drug information services, poisoning control services, therapeutic drug monitoring services, orthopedic services, oncology pharmacy services, pharmacoeconomic services and pain management services. All pharmacists should document the clinical pharmacy activities on a monthly basis; the clinical activities consisted of central clinical pharmacy activities, patient-specific clinical pharmacy activities, administrationspecific clinical pharmacy activities and time spent for each activity. ${ }^{3,16,18}$ The clinical pharmacy program was established during the mid-1980s at the biggest public Ministry of Health hospital. 
Table 1: Estimated cost efficiency of clinical pharmacy services (USD).

\begin{tabular}{|l|c|c|c|c|c|c|c|}
\hline \multicolumn{1}{|c|}{ Month } & $\begin{array}{c}\text { Cost avoidance } \\
\text { of Drug } \\
\text { Information } \\
\text { Services }\end{array}$ & $\begin{array}{c}\text { Cost avoidance } \\
\text { of Poisoning } \\
\text { services }\end{array}$ & $\begin{array}{c}\text { Cost avoidance } \\
\text { of Other clinical } \\
\text { pharmacy } \\
\text { services }\end{array}$ & $\begin{array}{c}\text { Total cost } \\
\text { avoidance }\end{array}$ & $\begin{array}{c}\text { Total salary } \\
\text { payment }\end{array}$ & $\begin{array}{c}\text { Estimated cost } \\
\text { avoidance } \\
\text { monthly } \\
\text { mosD invested } \\
\text { would save } \\
\text { monthly }\end{array}$ \\
\hline 1 & $2,629,050.00$ & $9,000,000.00$ & $7,500,000.00$ & $19,129,050.00$ & $108,490.00$ & $19,020,560.00$ & 175.32 \\
\hline 2 & $3,775,396.88$ & $787,599.00$ & $1,294.00$ & $11,651,690.86$ & $125,490.00$ & $11,526,200.86$ & 91.85 \\
\hline 3 & $3,756,720.00$ & $8,625,000.00$ & $2,293.20$ & $12,384,013.20$ & $125,490.00$ & $12,258,523.20$ & 97.69 \\
\hline 4 & $4,127,266.88$ & $9,000,000.00$ & $19,316.56$ & $13,146,583.43$ & $125,490.00$ & $13,021,093.43$ & 103.76 \\
\hline 5 & $3,378,841.88$ & $6,750,000.00$ & $1,263.60$ & $10,130,105.48$ & $125,490.00$ & $10,004,615.48$ & 79.72 \\
\hline Total & $17,667,275.64$ & $34,162,599.00$ & $7,524,167.36$ & $66,441,442.97$ & $610,450.00$ & $65,830,992.97$ & 107.84 \\
\hline $\begin{array}{l}\text { Average cost avoidance } \\
\text { monthly }\end{array}$ & $3,533,455.13$ & $6,832,519.80$ & $1,504,833.47$ & $13,288,288.59$ & $122,090.00$ & $13,166,198.59$ \\
\hline $\begin{array}{l}\text { Average cost avoidance } \\
\text { monthly per occupied bed }\end{array}$ & $2,523.90$ & $4,880.37$ & $1,074.88$ & $9,491.63$ & 87.21 & 107.84 \\
\hline
\end{tabular}

The hospital has 1400 beds and three hospitals: public, pediatrics and maternity and obstetric hospitals. The hospital had started with two clinical pharmacists at medical and surgical wards. Then, the services were expanded to cover drug information services and drug researches. In 1998, nutrition support pharmacy was started for adult patients. During 2008-2012, the clinical pharmacy services expanded with more than 10 clinical pharmacists. Currently, more than 20 clinical pharmacists provide pharmaceutical care in the hospital. The author calculated the estimated cost avoidance by using two International Studies Model, expressed in terms of US dollars (USD); the costs avoidance considered were the expected results of drug-related problems of drug information inquiries, poisoning information calls if not resolved and cost avoidance of pharmacist intervention for all other clinical pharmacy services. ${ }^{19,20}$

\section{RESULTS}

A total average estimated monthly cost avoidance from all clinical services $(13,166,198.59$ USD) with cumulative cost avoidance was $65,830,992.97$ USD during the study period. The estimated total cost avoidance annually was $157,994,383.08$ USD. The highest cost avoidance came from poisoning services, whose estimated cost avoidance was $51.4 \%(6,832,519.80$ USD), followed by drug information services, whose estimated cost avoidance was $26.59 \%$ (3,533,455.13 USD) and other clinical pharmacy services, whose estimated cost avoidance was $11.32 \%(1,504,833.47$ USD) of the total. The average estimated avoidance/occupied bed was 9404.43 USD, whereas the poisoning services was 4880.37 USD and drug information was 2523.90 USD and other clinical pharmacy services was 1074.88 USD (Table 1). Each USD invested in the clinical pharmacist estimated cost avoidance was an average of 107.84 USD. Each USD invested in the clinical pharmacist provides poisoning control services estimated cost avoidance was an average of 55.96 USD. Each USD invested to the clinical pharmacist provide drug information services estimated cost avoidance was an average of 28.94 USD. Each USD invested to the other clinical pharmacist provides other clinical pharmacy services estimated cost avoidance was an average of 12.32 USD (Table 1).

\section{DISCUSSION}

Clinical pharmacy program has been established at the biggest Ministry of Health hospital since mid-1980s. ${ }^{1,2}$ The hospital has 1400 beds and three hospitals: public, pediatrics and maternity and obstetric hospitals. The hospital was started with two clinical pharmacists at medical and surgical wards. The services were expanded to cover drug information and drug researches. In 1998, nutrition support pharmacy was started for the adult patients. During 2008-2012, the clinical pharmacy services was expanded with more than 10 clinical pharmacists. More than 20 clinical pharmacists provide pharmaceutical care at all hospitals. In this study, the authors tried to estimate the cost of clinical pharmacy services through the clinical pharmacists. The findings showed a highcost impact of clinical pharmacy services. Our results were lower than the previous study because of the well-established services at the study site studies, whereas it was newly established at our current site. ${ }^{15,16}$ The maximum high-cost impact was from drug information and poisoning services. Therefore, these services have been provided for a long time in the current study site, whereas the other clinical activities or services were newly founded. The estimated cost avoidance per occupied bed was higher than the previous study, whereas it was lower than the updated study. This is related the incremental number of hospital in the study and well-established clinical pharmacy services. ${ }^{15,16}$ The rate of cost invested in saving money was higher than the previous study. ${ }^{15}$ Because there maybe high number or intervention or the potential of the interventions of newly established clinical activities. Moreover, the hospitals had very few newly appointed clinical pharmacists with more active and more involvement in the $\mathrm{f}$ the therapeutic plan. In addition, the hospital missed to follow several therapeutic guidelines at that time; that's may lead more intervention and correction the inappropriate medication usage. The clinical pharmacy services at the local hospital are cost-efficient and need to expand the services to cover all beds to provide best care to the patients.

\section{CONCLUSION}

In this study, clinical pharmacy services were cost-efficient at biggest public hospital in Riyadh city, Saudi Arabia. This is associated with cost savings per clinical pharmacist. In future, we recommend to expand the clinical pharmacy services with electronic documentation, related to preventing drug-related problems, emergency units visiting and drug-related hospital admission. In addition, cost avoidance simulation should be performed for healthcare improvement and better care, better patient outcomes and reduced costs.

\section{ACKNOWLEDGEMENT}

None. 


\section{CONFLICT OF INTEREST}

The authors declare no conflict of interest.

\section{ABBREVIATIONS}

MEs: Medication Errors; UK: United Kingdom; MOH: Ministry of Health; ISMP: Institute Safety Medication Practice; NCC: National Coordinating Council; MERP: Medication Error Reporting and Prevention; KSA: Kingdom of Saudi Arabia; USD: United State Dollars.

\section{ORCID ID}

Yousef Ahmed Alomi, (D) https://orcid.org/0000-0003- 1381-628X

\section{REFERENCES}

1. Alomi YA. National Medication Safety Program at Ministry of Health in Saudi Arabia. J Pharmacovigil. 2015;3(5):e145.

2. Alomi YA. National Drug Information Center Program at Ministry of Health in Saudi Arabia. Adv Pharmacoepidemiol Drug Saf. 2016;5(1):1-2.

3. Bond CA, Raehl CL. Clinical pharmacy services, pharmacy staffing and hospital mortality rates. Pharmacotherapy. 2007;27(4):481-93.

4. Alomi YA, Almudaiheem HY, Alarnous $T$, Alshurei $S$, Alsharafa A, Alzahrani $T$ et al. Cost-efficiency of of National Drug Information Center Through Ministry of Healh Hotline Calling Services (937) in Saudi Arabia: Application of a Mercian Model. Value Heal. 2015;18(7):A735.

5. Alomi YA, Mudaiheem HA. National Drug Information Center Services through Ministry of Health Hotline Calling Center (937) in Saudi Arabia. Adv Pharmacoepidemiol Drug Saf. 2016;5(1):1-7.

6. Alomi YA, Fallatah AO. Cost Avoidance of Pharmacist Running Pediatrics Total Parenteral Nutrition Services at Ministry of Health in Saudi Arabia. Value Heal. 2016;19(7):A461

7. Alomi YA, Almudaiheem HY. Clinical outcomes of Vancomycin therapeutic monitoring services at Ministry of Health hospital in Saudi Arabia. Value Heal 2017;20(5):A42
8. Alomi YA, Fallatah AO, Al-Smail EH. Assessment of Clinical and Economic Outcomes of Pharmacist Intervention in Total Parenteral Nutrition Program in Saudi Arabia. Value Heal. 2016;19(7):A465.

9. Alomi YA, El-Bahnasawi M, Shaweesh T, Kamran M, Elgaili SH, Elemam A, et al. Clinical and Economic outcomes of clinical pharmacist at adults critical care of private hospital in Saudi Arabia. Value Heal. 2017;20(5):A37.

10. Alomi YA, Almudaiheem HY. Clinical and Economic Outcomes of Pharmacist Intervention During Therapeutic Drug Monitoring Program in Saudi Arabia. Value Heal. 2016;19(7):A465-6.

11. AlomiYA, Al-Shubbar NA, Lubad NA. Inpatient Medication Errors and Pharmacist Intervention at Ministry of Health Public Hospital in Riyadh, Saudi Arabia. Value Heal. 2017;20(9):A690.

12. Alomi YA, Alanazi AA, Alsallouk SA, Almaznai MM, Abu-Alnaja NI, Alduhilan M, et al. Cost-efficiency of Medication Safety Program at Pediatrics, Obstetrics and Gynecology Hospital, East Province, Saudi Arabia. Value Heal. 2016;19(7):A464

13. AlomiYA, Al-Shubbar NA, Lubad NA. Economics outcomes of medication safety program at public hospital in Riyadh, Saudi Arabia. In Value Heal. 2017;20(5):A32.

14. Bond CA, Raehl CL, Franke T. Clinical pharmacy services, pharmacy staffing and the total cost of care in United States hospitals. Pharmacotherapy. 2000;20(6):609-21.

15. Bond CA, Raehl CL, Franke T. Clinical pharmacy services, pharmacist staffing and drug costs in United States Hospitals. Pharmacotherapy. 1999;19(12):1354-62.

16. Bond CA, Raehl CL, Franke T. Clinical Pharmacy Services, Pharmacy Staffing and the Total Cost of Care in United States Hospitals. Pharmacotherapy. 2002;22(2):134-47.

17. Gallagher J, McCarthy S, Byrne S. Economic evaluations of clinical pharmacist interventions on hospital inpatients: a systematic review of recent literature. Int J Clin Pharm. 2014;36(6):1101-14.

18. Bond CA, Raehl CL, Franke T. Clinical Pharmacy Services, Pharmacist Staffing and Drug Costs in United States Hospitals. Pharmacotherapy. 1999;19(12):1354-62.

19. Kinky DE, Erush SC, Laskin MS, Gibson GA, Alomi Y. Economic Impact of a Drug Information Service D. Ann Pharmacother. 1999;33(1):11-6.

20. Ling JM, Mike LA, Rubin J, Abraham P, Howe A, Patka J, et al. Documentation of pharmacist interventions in the emergency department. Am J Heal Pharm. 2005;62(17):1793-7. 